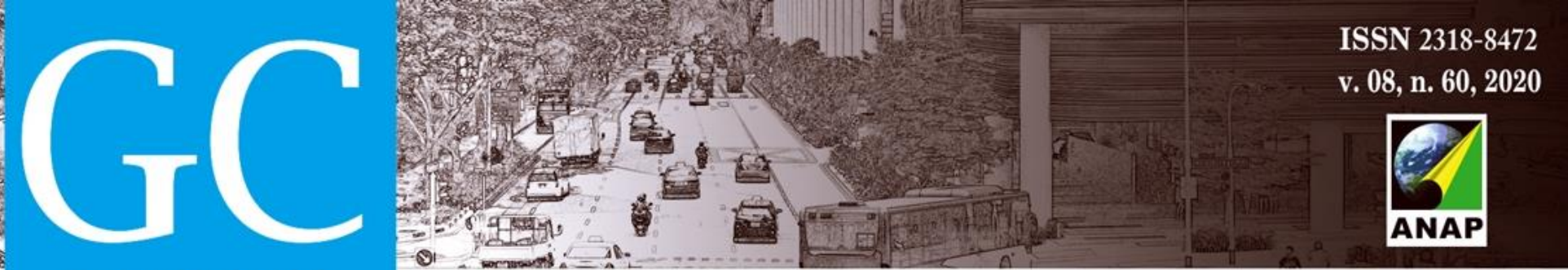

\title{
Revista Nacional de
}

Gerenciamento de Cidades

Mapeamento de áreas de risco de contaminação por agrotóxicos: um estudo de caso no estado do Espírito Santo, Brasil

Mapping areas at risk of contamination by pesticides: a case study in the state of Espirito Santo, Brazil

Mapeo de áreas enriesgo de contaminación por pesticidas: unestudio de caso enel estado de Espírito Santo, Brasil

Luan Carlos Octaviano Ferreira Leite

Mestrando em Ambiente Construído, UFJF, Brasil luan.octaviano@engenharia.ufjf.br

Renata de Oliveira Pereira Professora Doutora, UFJF, Brasil renata.pereira@ufjf.edu.br

Jonathas Batista Gonçalves Silva

Professor Doutor, UFJF, Brasil jonathas.silva@ufjf.edu.br 


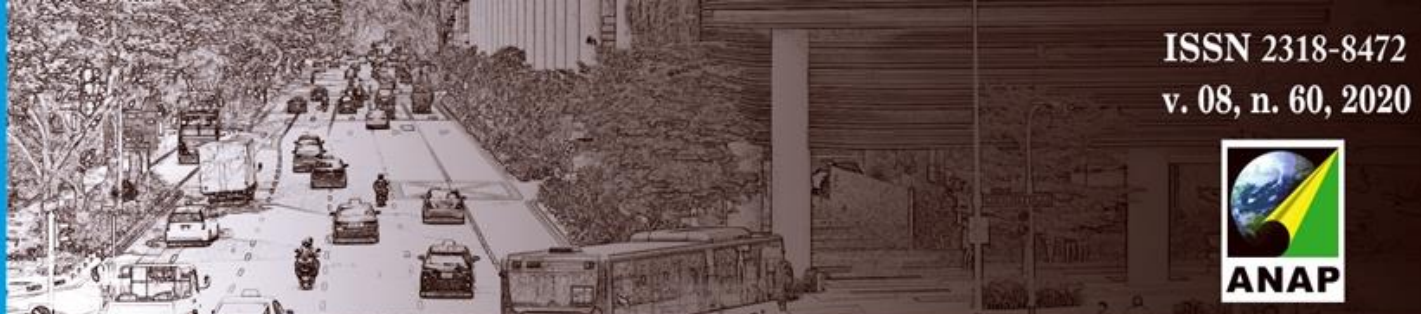

Revista Nacional de

Gerenciamento de Cidades

\section{INTRODUÇÃO}

O uso de agrotóxicos é um importante pilar para sustentação das práticas agrícolas contemporâneas (Montagner et al., 2014). O Brasil tem se destacado ao longo dos anos no cenário mundial do consumo destas substâncias. Segundo Moraes (2019) o país partiu de um consumo de 58 mil toneladas em 1991, chegando a 375 mil toneladas em 2015, sendo sozinho responsável por 9,2\% do consumo mundial, ficando atrás apenas dos Estados Unidos com 9,9 \% e da China, maior consumidor, responsável por $43,6 \%$ do consumo mundial em 2015. Dados do IBAMA (2020) demonstram que o consumo de agrotóxicos no Brasil segue aumentando, chegando a mais de 549 mil toneladas comercializadas em seu território no ano de 2018.

O número de registros de novos princípios ativos tem acompanhado o aumento de consumo. Segundo dados do Ministério da Agricultura Pecuária e Abastecimento (MAPA) a quantidade de novas substâncias registradas cresceu desde 2005, indo de 90 novos registros concedidos em 2005 para 139 em 2015, ano a partir do qual o número de produtos registrados aumentou numa escala sem precedentes e sem nenhuma queda desde então, atingindo 474 novos registros no ano de 2019 (MAPA, 2020). Quando esses novos produtos apresentam modos de ação mais seguros e com menor toxicidade, podem reduzir os efeitos indesejados na saúde humana e no ambiente (Damalas \& Eleftherohorinos, 2011). Porém, seu uso desordenado tem se tornado preocupante tanto do ponto de vista de saúde pública quanto do ponto de vista ambiental.

Apesar de promoverem aumento na capacidade de oferta de alimentos, vale salientar que existem diversos impactos negativos atrelados ao uso dos agrotóxicos (Porto \& Milanez, 2009). Dentre as principais consequências da exposição humana a essas substâncias podem ser citados problemas do sistema respiratório como asma, problemas de ordem neurológica como Doença de Parkinson e distúrbios cognitivos; desordens hormonais e reprodutivas; doenças crônicas; diabetes; danos no DNA; alterações cromossômicas; mutações genéticas e câncer (Bolognesi \& Merlo, 2019; Dhananjayan \& Ravichandran, 2018; Ji et al., 2020; Kim, Kabir, \& Jahan, 2016; Lopes \& Albuquerque 2018). Além de riscos à saúde pública, a utilização de agrotóxicos traz riscos para o ambiente através da contaminação de componentes bióticos e abióticos dos ecossistemas (água, ar, biota, solo, sedimentos, etc).Tais impactos ocorrem através da modificação em curto ou longo prazo, do funcionamento normal de um ecossistema, gerando assim, perdas de ordem econômica, social e estética (Peres, Moreira \& Dubois, 2003; Parween \& Jan, 2019).

Avaliar os riscos associados ao uso destas substâncias se torna de grande valor tendo em vista seus efeitos negativos sobre o ambiente e a saúde humana (Queiroz et al. 2018). Da mesma forma, informações confiáveis são de grande valor para subsidiar o planejamento e as tomadas de decisão, sendo fundamentais para sua efetividade. Entretanto, são observados entraves neste setor, como deficiências em dados georreferenciados e dificuldades na integração de departamentos e setores de diferentes áreas, que se restringem a situações de surto (Queiroz et al., 2012). Segundo Damalas \& Eleftherohorinos (2011) diferentes indicadores têm sido utilizados para auxiliar nas avaliações de risco de agrotóxicos para a saúde e o ambiente. Contudo, seu uso tem sugerido a necessidade de criação de novos indicadores que tragam maior credibilidade e precisão a esse tipo de análise. Desta forma, 
Revista Nacional de Gerenciamento de Cidades

o presente estudo tem por objetivo propor uma metodologia baseada em indicadores e Sistemas de Informação Geográfica (SIG) para a identificação das culturas e áreas de risco de contaminação ambiental por agrotóxicos, assim como os principais agrotóxicos associados a tais culturas, utilizando o estado do Espírito Santo como estudo de caso.

\section{MATERIAL E MÉTODOS}

\section{1. ÁREA DE ESTUDO}

O Espírito Santo é uma das unidades federativas do Brasil, localizada na região Sudeste do país, fazendo divisa ao sul com o estado do Rio de Janeiro, a oeste com Minas Gerais e a norte com a Bahia, sendo banhado a leste pelo oceano Atlântico (Figura 1). Localiza-se a oeste do Meridiano de Greenwich e ao sul da Linha do Equador, com fuso horário de menos três horas em relação à hora mundial GMT. A extensão territorial é de $46.074,444$ km² com uma população de 3.514 .952 habitantes no último censo (2010), estimada para 4.018.650 de pessoas no ano de 2019 (IBGE, 2020a).

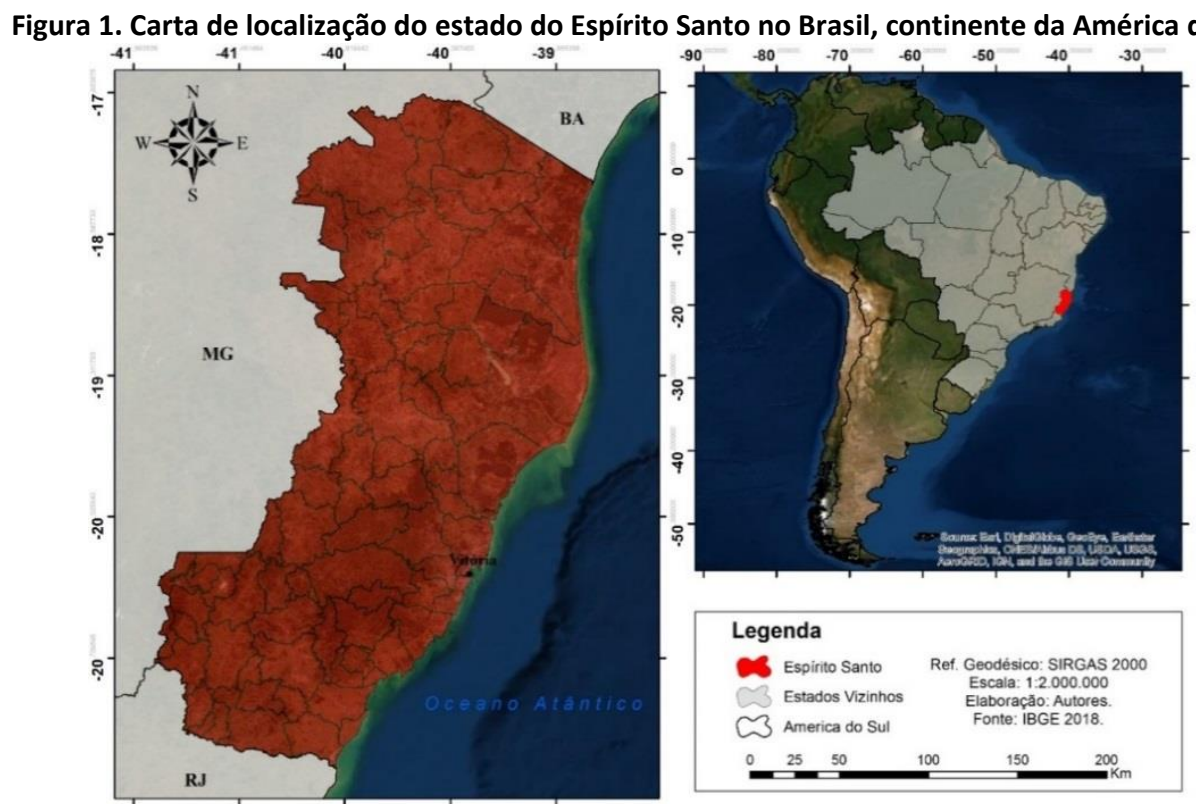

Fonte: Autores, 2020

O estado do Espírito Santo foi a região escolhida como estudo de caso, devido a seu reduzido número de municípios, apenas 78 e, principalmente, devido à existência do banco de dados sobre agrotóxicos do Instituto de Defesa Agropecuária e Florestal (IDAF). Tal banco de dados permite a triagem dos agrotóxicos autorizados para cada cultura agrícola no estado, atribuindo maior confiabilidade ao método proposto uma vez que, sem ele, seria possível determinar os agrotóxicos autorizados para as culturas apenas a nível nacional o que poderia levar a análises com ingredientes ativos (I.A.'s) que, apesar de autorizados a nível nacional, podem não ser permitidos em um determinado estado. 


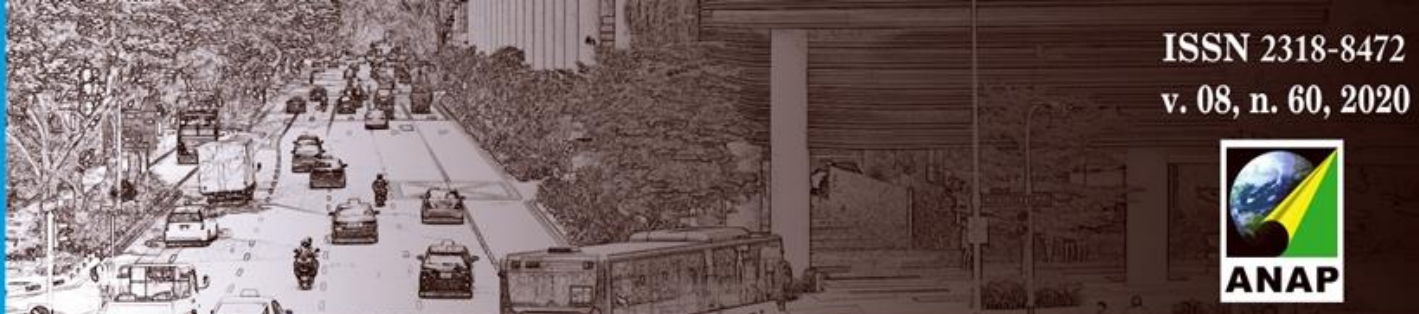

Revista Nacional de

Gerenciamento de Cidades

\subsection{DEFINIÇÃO DOS INDICADORES}

A metodologia proposta no presente estudo envolve a definição de indicadores que auxiliem na compreensão do risco de contaminação por agrotóxicos em um determinado município. Foram consultadas diferentes bases de dados geográficos para a obtenção das informações necessárias, que posteriormente passaram por etapas de preparação até a construção da base de dados final. Nas seguintes seções são descritos os procedimentos empregados em cada uma das etapas.

\subsubsection{LEVANTAMENTO DA PRODUÇÃO AGRÍCOLA}

Para a análise da produção agrícola do estado do Espírito Santo foram utilizados dados do Sistema IBGE de Recuperação Automática (SIDRA), do Instituto Brasileiro de Geografia e Estatística (IBGE, 2020b). Foram obtidas as extensões de área plantada (ha) e a produção (ton) para todas as culturas agrícolas produzidas nos municípios do estado entre os anos de 2007 e 2018. Foi calculada a área plantada total (ha) de cada cultura e estabelecido um percentil de $90 \%$ como um valor acima do qual encontram-se as culturas de maior representatividade no cenário estadual. As culturas com área plantada total maior que o percentil $90 \%$ foram selecionadas como prioritárias para a aplicação da metodologia proposta.

\subsubsection{ANÁLISE ESPACIAL DA PRODUÇÃO AGRíCOLA}

Os valores de área plantada total das culturas agrícolas mais significativas no cenário estadual determinadas na etapa anterior foram espacializados através do software ArcGis versão 10.2.1, para a construção do indicador "Área plantada". Foi utilizada como base uma malha digital com os limites político-administrativos do estado do Espírito Santo, disponibilizada pelo IBGE (2015). Esse procedimento teve o intuito de permitir uma análise da distribuição espacial das extensões de terra plantada com as culturas selecionadas ao longo dos municípios do estado, tornando visível a concentração de maiores plantios em determinadas regiões de seu território.

\subsubsection{DEMAIS INDICADORES}

Através do arquivo vetorial do Censo Agropecuário do IBGE (2019) foram obtidas as informações necessárias para a construção dos demais indicadores de risco de contaminação por agrotóxicos. Os indicadores selecionados do censo foram: "V- 34. Utilização de agrotóxicos"; "V-35. Despesa com agrotóxicos"; "V-16. Uso da terra por lavouras" e "V-1. Número de propriedades rurais". No Quadro 1 há uma descrição dos indicadores utilizados, com suas respectivas fontes e significados. 


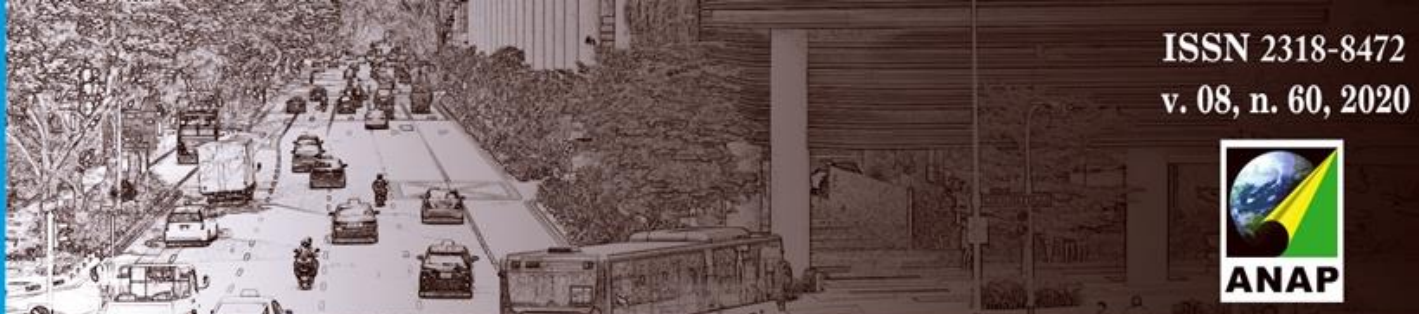

Revista Nacional de

Gerenciamento de Cidades

Quadro 1. Indicadores utilizados no estudo com seus respectivos significados e fontes.

\begin{tabular}{|c|c|c|}
\hline Indicador & Significado & Fonte \\
\hline Área plantada & $\begin{array}{l}\text { Somatório da área plantada (ha) anualmente com cada } \\
\text { cultura entre } 2007 \text { e } 2018 \text { em cada município. }\end{array}$ & $\begin{array}{l}\text { Sistema SIDRA - Produção } \\
\text { Agrícola Municipal (PAM) - } \\
\text { IBGE (2020B) }\end{array}$ \\
\hline $\begin{array}{l}\text { Utilização de } \\
\text { agrotóxicos }\end{array}$ & $\begin{array}{l}\text { Percentual de estabelecimentos } \\
\text { declaração de usopecuários } \\
\text { relação ao total de estabelecimentos agropecuários no } \\
\text { município em 2017. }\end{array}$ & $\begin{array}{l}\text { Censo } \quad \text { Agropecuário } \\
\text { Brasileiro - IBGE (2019). }\end{array}$ \\
\hline $\begin{array}{l}\text { Despesa com } \\
\text { agrotóxicos }\end{array}$ & $\begin{array}{l}\text { Participação da despesa com agrotóxicos na despesa total } \\
\text { do estabelecimento agropecuário, } \\
\text { por município em } 2017 \text {. }\end{array}$ & $\begin{array}{l}\text { Censo Agropecuário } \\
\text { Brasileiro - IBGE (2019). }\end{array}$ \\
\hline $\begin{array}{l}\text { Uso da terra para } \\
\text { lavoura }\end{array}$ & $\begin{array}{l}\text { Percentual da área do município coberta por lavouras em } \\
2017 .\end{array}$ & $\begin{array}{l}\text { Censo } \quad \text { Agropecuário } \\
\text { Brasileiro - IBGE (2019). }\end{array}$ \\
\hline $\begin{array}{l}\text { Estabelecimentos } \\
\text { agropecuário }\end{array}$ & $\begin{array}{l}\text { Total de estabelecimentos agropecuários, por município em } \\
2017 .\end{array}$ & $\begin{array}{l}\text { Censo } \quad \text { Agropecuário } \\
\text { Brasileiro - IBGE (2019). }\end{array}$ \\
\hline
\end{tabular}

\subsection{CONSTRUÇÃO DA BASE DE DADOS}

A partir dos dados vetoriais gerados nas etapas de análise espacial da produção agrícola e dos indicadores selecionados do Censo Rural, foi construída a base de dados utilizada para a análise final. Cada indicador selecionado no Censo Agropecuário foi individualizado em um arquivo shapefile, com exceção do indicador "Área Plantada" que já foi especializado em um shapefile separado. Os arquivos vetorias posteriormente foram convertidos para o formato raster. Os arquivos raster passaram por um processo de classificação por intervalos iguais, dividindo os valores de cada indicador em 5 classes dos menores aos maiores, que receberam valores de 1 a 5 conforme o risco que representam. As classes dos menores valores de cada indicador receberam valor 1 , como sendo de um risco muito baixo, aumentando gradativamente até as classes dos valores maiores, que receberam valor 5 , como sendo um risco muito alto. Uma vez classificados, os arquivos raster passaram a representar os planos de informações utilizados no processo de sobreposição ponderada.

\subsection{SOBREPOSIÇÃO DOS PLANOS DE INFORMAÇÃO}

Para a sobreposição foi utilizada a ferramenta Weighted Overlay, que realiza uma média ponderada entre os valores dos pixels dos planos de informação sobrepostos que representam um mesmo ponto no espaço. Para a utilização dessa ferramenta, é necessário definir peso adequado para cada uma das variáveis envolvidas no processo, função que fica a critério dos responsáveis pela análise. Desta forma, foi adotado o método Analytic Hierarchy Process (AHP), onde realiza-se uma comparação pareada entre as variáveis que determinam o fenômeno estudado e, através da atribuição de graus de igualdade ou de preferência entre as variáveis, são gerados os pesos mais adequados para cada plano de informação (Estoque, 2012). Este procedimento foi realizado com a extensão AHP do ArcGis, que realiza o processo de forma automática, sem necessidade de uso de outra plataforma. No quadro 2 estão os pesos encontrados para cada plano de informação: 


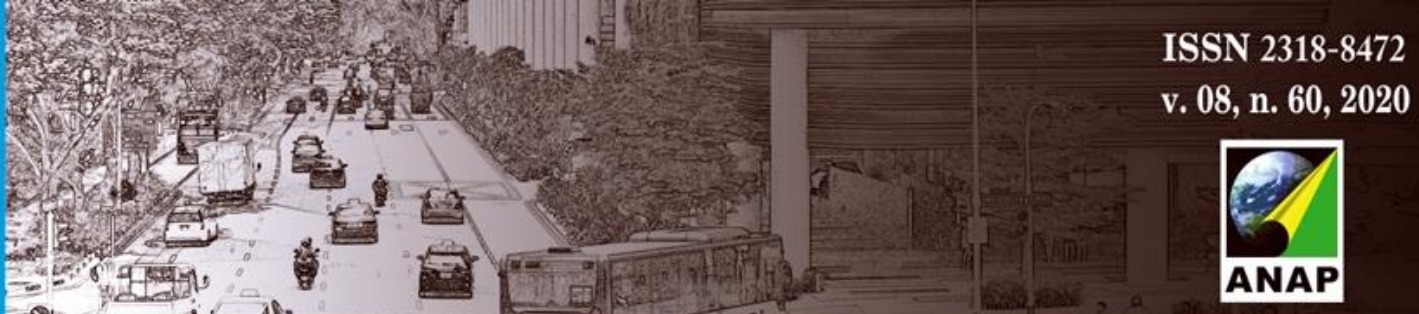

Revista Nacional de

Gerenciamento de Cidades

Quadro 2. Pesos atribuídos aos planos de informação dos indicadores através do método AHP.

\begin{tabular}{c|c}
\hline Plano de Informação & Peso definido pelo método AHP \\
\hline Área plantada & 43,026 \\
\hline Utilização de agrotóxicos & 29,640 \\
\hline Despesas com agrotóxicos & 17,247 \\
\hline Uso da terra para lavoura & 5,484 \\
\hline Estabelecimentos agropecuários & 4,603 \\
\hline
\end{tabular}

Fonte: Autores.

Os planos de informações "Área plantada" de cada uma das culturas prioritárias foram sobrepostos individualmente com os demais planos "Utilização de agrotóxicos", "Despesa com agrotóxicos", "Uso da terra para lavoura" e "Estabelecimentos agropecuários". Os resultados do processo de sobreposição foram mapas classificados indicando os municípios de baixo, médio e alto risco de contaminação por agrotóxicos, baseados em cada uma das culturas específicas.

\subsection{MAPA SÍNTESE}

Os resultados obtidos individualmente para cada uma das culturas foram sintetizados em um único mapa. O objetivo deste mapa é indicar aqueles municípios onde existe maior ou menor risco de contaminação ambiental por agrotóxicos considerando as principais culturas agrícolas do estado de forma generalizada. Neste procedimento foi utilizada a ferramenta Weighted Sum, que realiza uma soma dos valores atribuídos aos pixels dos planos de informação sobrepostos. Foi definido peso 1 para todos os planos de informação, de forma que nenhuma variável interfira mais que as demais no resultado final. Uma vez que os resultados dos mapeamentos individuais de cada cultura apresentam 3 classes, sendo: 1 - Baixo Risco, 2 - Médio Risco e 3 - Alto Risco, o resultado do mapa síntese varia entre 4, quando o município apresenta baixo risco para todas as culturas selecionadas e 12 , caso o município apresente alto risco para todas culturas selecionadas. Desta forma, o arquivo de saída do processo de soma foi divido em 3 classes iguais, sendo: 4 a 6 - Baixo Risco, 7 a 9 - Médio Risco e 10 a 12 - Alto Risco.

\subsection{DETERMINAÇÃO DOS PRINCIPAIS AGROTÓXICOS ASSOCIADOS AS CULTURAS}

Para a determinação dos principais agrotóxicos autorizados no estado para as culturas indicadas no presente estudo foram consultadas as bases de dados do Instituto Brasileiro de Meio Ambiente e Recursos Naturais Renováveis (IBAMA, 2020) e do IDAF (2020). Na seção de agrotóxicos do IBAMA foram obtidos os totais comercializados, em toneladas, para cada I.A. entre os anos de 2009 e 2018 no estado do Espírito Santo. Através do somatório dos valores totais comercializados de cada I.A., foi possível determinar aqueles com maior consumo em seu território. Cabe destacar que ao longo do período analisado alguns I.A.'s podem ter perdido seu registro para comercialização. Desta forma, através de consulta ao sistema de agrotóxicos do IDAF foi verificada a autorização de cada um dos I.A.'s, sendo desconsiderados da análise aqueles que não se encontravam devidamente registrados no momento da análise (abril de 2020). Também foram desconsiderados os agentes microbiológicos e os adjuvantes óleo mineral e óleo vegetal por não se tratarem especificamente de agrotóxicos químicos. 


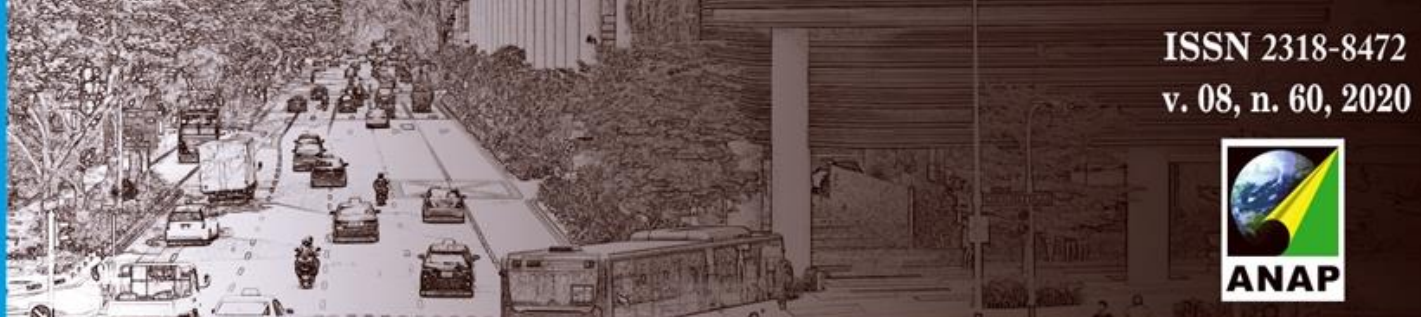

Revista Nacional de

Gerenciamento de Cidades

Foram considerados como I.A.'s de risco os 5 compostos de maior comercialização dentre aqueles registrados para uso em cada uma das culturas. No sistema de agrotóxicos do IDAF também foi consultado o número de agrotóxicos registrado para cada uma das culturas, de forma a indicar aquela ou aquelas que possuem mais agrotóxicos passíveis de uso nos municípios do estado e que, potencialmente, expõem a maiores riscos o ambiente e a população local.

\section{RESULTADOS}

\subsection{DETERMINAÇÃO DAS CULTURAS E ÁREAS DE RISCO}

Conforme a análise das informações do sistema SIDRA do IBGE, observou-se que foram cultivadas 34 culturas no estado do Espírito Sando no período entre 2007 e 2018, das quais 21 são culturas permanentes e 13 são culturas temporárias. Em relação à área plantada, considerando o percentil $90 \%$, as principais culturas no cenário estadual são o café, a cana-de-açúcar, o milho e banana. 0 café encontra-se em primeiro lugar, com um total de 5.202.368 hectares plantados entre os anos de 2007 a 2018. A cana-de-açúcar, segunda colocada no ranking de área planta, teve um total de 857.612 hectares plantados, valor aproximadamente 6 vezes menor que o do café, apesar de apresentar uma produção 6 vezes maior. 0 milho se encontra em terceiro lugar, com 276.472 ha plantados, seguido pela banana com 266.286 ha.

Conforme o mapeamento do risco de contaminação por agrotóxicos associado à cultura do café (Figura 2), 10 municípios são enquadrados na classe de alto risco, são eles: Nova Venécia, na mesorregião noroeste do estado, São Mateus, Jaguaré, Vila Valério, Sooretama, Rio Bananal e Linhares, inseridos na mesorregião do litoral norte espírito-santense, Afonso Cláudio e Brejetuba na mesorregião central e lúna, na mesorregião sul do estado. A região do litoral norte é a que concentra o maior número de municípios com alto risco de contaminação de agrotóxicos associados ao café, com 6 municípios. A área total classificada como de alto risco é de 1.134 .880 ha, correspondendo a 25 $\%$ do território do estado. A classe de médio risco é a que abrange mais municípios, um total de 47 , cobrindo $55 \%$ do território do estado ( $2.515 .533 \mathrm{ha}$ ) enquanto a classe de baixo risco abrange 21 municípios, $21 \%$ das terras do estado (943.453 ha).

Se ranqueados em ordem decrescente conforme o total de área plantada com café, no cenário estadual, os municípios classificados como de alto risco são: 10 Vila Valério (231.100 ha), 2ำ Jaguaré (224.350 ha), 3ํ Nova Venécia (197.798 ha), 4ㅇ Sooretama (186.735 ha), 5o Rio Bananal (166.845 ha), 60 Linhares (162.904 ha), 7o Brejetuba (151.880 ha), 8 São Mateus (151.844 ha), $9^{\circ}$ lúna (145.218 ha) e 10ㅇ Afonso Cláudio (139.774 ha). Em termos de produção em toneladas, se ordenados da mesma maneira, os municípios indicados como de alto risco possuem as seguintes colocações: $1^{\circ}$ Jaguaré (402.372 ton), 2ํ Vila Valério (380.017 ton), 3 Sooretama (337.249 ton), 4 Nova Venécia (310.706 ton), 5 Linhares (306.081 ton), 6으 Rio Bananal (301.844 ton), 70 Brejetuba (250.903 ton), 8ㅇ São Mateus (249.028 ton), $11^{\circ}$ lúna (200.764 ton) e 20 Afonso Cláudio (168.839 ton). 
Revista Nacional de

Gerenciamento de Cidades

Figura 5. Mapa de risco de contaminação ambiental por agrotóxicos associados a cultura da banana no estado do Espírito Santo, Brasil.

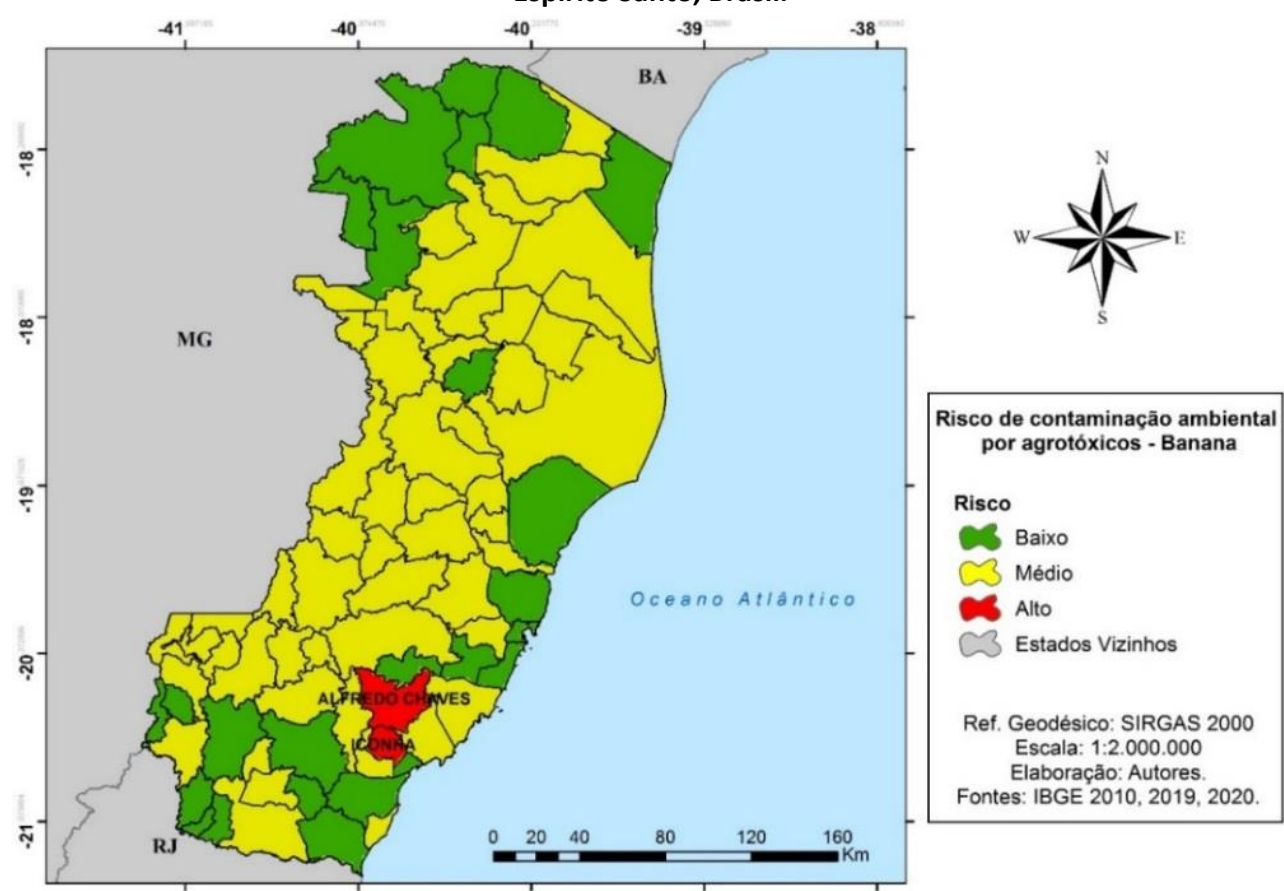

Fonte: Autores, 2020

Ao confrontar os resultados do mapeamento, nota-se que o café é a cultura que possui maior risco associado de contaminação ambiental por agrotóxicos no estado do Espírito Santo entre as culturas analisadas. O seu número de municípios classificados como de alto risco é 5 vezes superior as demais culturas. Sua extensão de terras classificadas como de alto risco é aproximadamente 2 vezes superior que a cana-de-açúcar, 5 vezes superior ao milho e mais de 10 vezes superior a banana.

O estado é o segundo maior produtor de café do Brasil, ficando atrás apenas do estado de Minas Gerais, apesar de ser líder nacional no que se trata da variedade conilon (Ferrão et al., 2017). O café foi responsável, sozinho, por 36,2 \% e 38,9 \% do valor bruto da produção agropecuária no estado nos anos de 2016 e 2017, respectivamente (Galeano, 2017; Galeano et al., 2018). Tal fato demonstra a importância da cultura no cenário estadual e sugere a necessidade de cautela no uso de agrotóxicos em seu manejo. $O$ mesmo se aplica à cana-de-açúcar, que apesar de ter menos municípios de alto risco que o café, é líder estadual em termos de produção. Sua extensão de terras de alto risco é mais de 2 vezes maior que a do milho e 5 vezes superior à da banana.

Em contrapartida, milho e banana são as culturas que apresentam menor risco associado ao uso de agrotóxicos no estado. O milho possui o maior número de municípios classificados como de baixo risco, assim como a maior extensão de terras inseridas nesta classe dentre as culturas analisadas. A banana, por sua vez, é a cultura com a menor extensão de terras classificadas como de alto risco apesar de apresentar uma extensão de terras inseridas na classe de médio risco maior que todas as outras culturas. Tais resultados sugerem que apesar do menor risco relacionado ao milho e a banana, não devem ser desconsideradas as boas práticas e cautela no uso de agrotóxicos. 


\section{Revista Nacional de}

Gerenciamento de Cidades

Quanto ao mapa síntese dos riscos de contaminação ambiental por agrotóxicos no estado (Figura 6), nota-se que predominam as áreas de médio risco, de forma similar aos resultados individuais de cada cultura, abrangendo 51 municípios, uma área total de 2.799 .990 ha, representando 61 \% do território do estado. A classe de baixo risco está sem segundo lugar, abrangendo 25 municípios, com uma área de 1.349.317 ha, aproximadamente $29 \%$ do território do estado. A classe de alto risco é a de menor abrangência, apenas 2 municípios, uma área de 439.125 ha, 10 \% do território do estado.

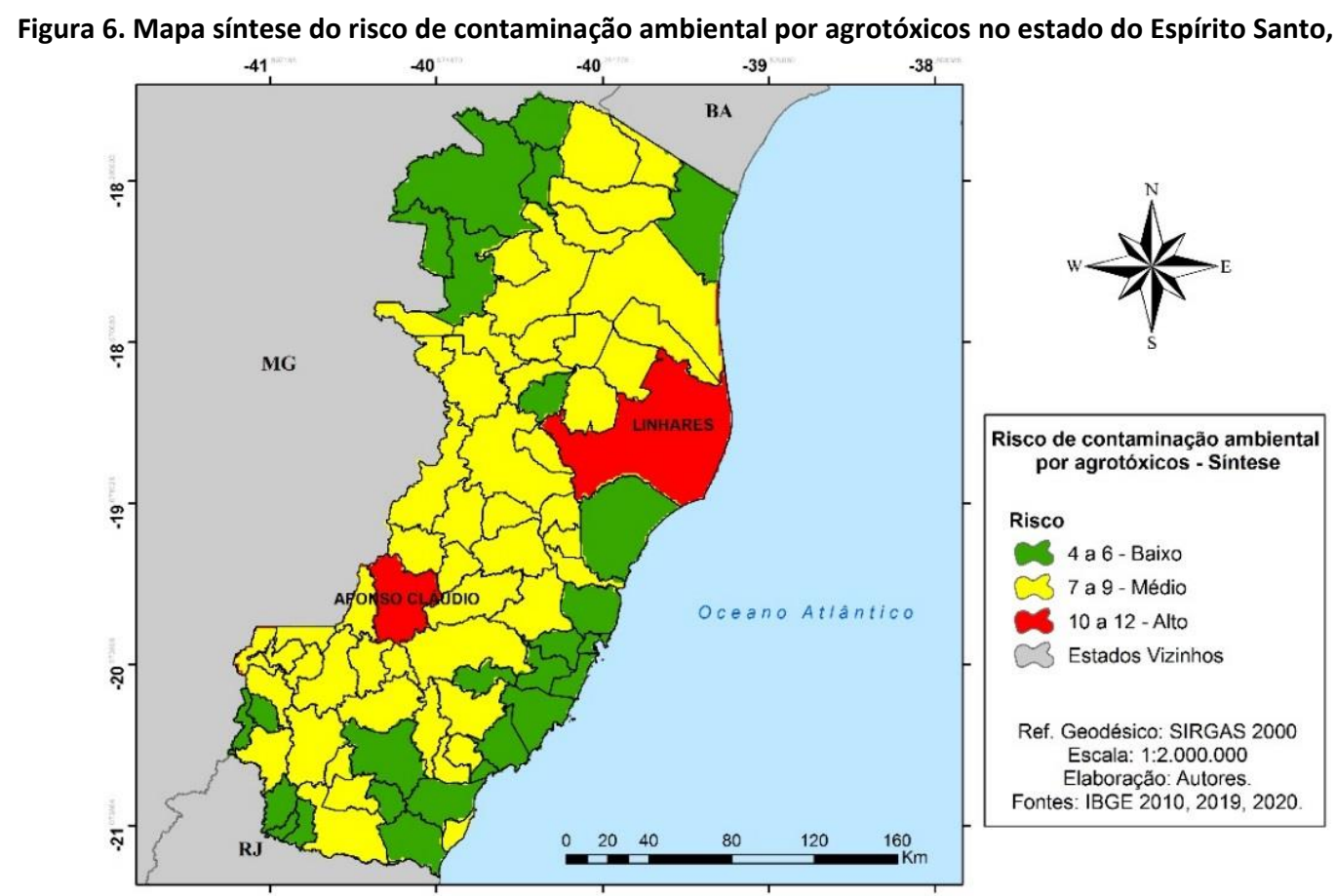

Fonte: Autores, 2020.

Os municípios inseridos na classe de alto risco são Linhares e Afonso Cláudio. Cabe destacar que nenhum dos dois municípios inclusos nesta classe foram considerados de alto risco para todas as culturas. Linhares, na verdade, apresenta alto risco associado ao café e a cana-de-açúcar, enquanto apresenta médio risco para milho e banana. Afonso Cláudio, por sua vez, apresenta alto risco associado ao café e o milho, e médio risco associado a cana-de-açúcar e banana. Quantos aos municípios classificados como de baixo risco, 15 dos 25 apresentam baixo risco para todas as culturas, são eles: Apiacá; Atilio Vivacqua; Bom Jesus do Norte; Divino de São Lourenço; Ecoporanga; Marechal Floriano; Mucuri; Piúma; Ponto Belo; Presidente Kennedy; São José do Calçado; Serra; Viana; Vila Velha e Vitória.

Os resultados obtidos nestes municípios se dão devido seu baixo potencial agrícola. Dos 15 municípios citados, 13 se encontram entre os 15 menores totais de área plantada no estado (Apiacá, Atilio Vivacqua, Bom Jesus do Norte, Divino de São Lourenço, Ecoporanga, Mucurici, Piúma, Ponto Belo, São José do Calçado, Serra, Viana, Vila Velha e Vitória); 8 se encontram entre as 11 menores despesas com agrotóxicos no estado (Bom Jesus do Norte, Ecoporanga, Piúma, Ponto Belo, São José do Calçado, 


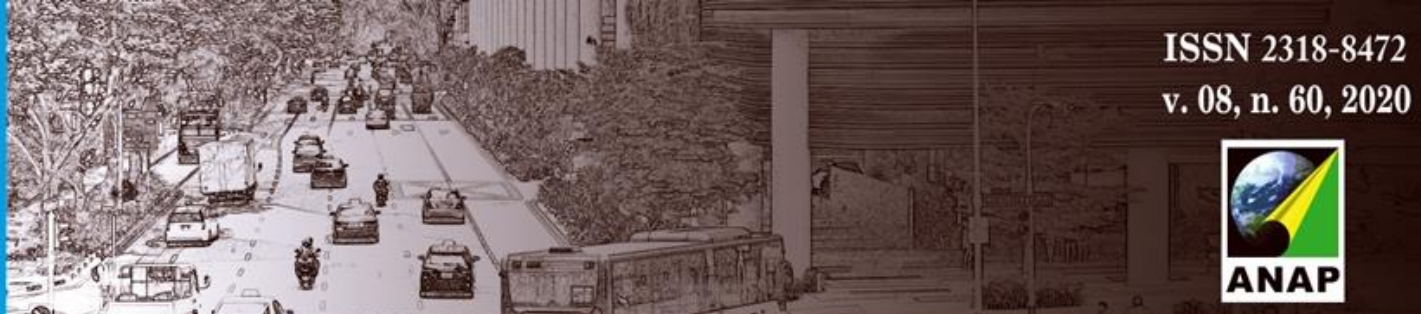

Revista Nacional de

Gerenciamento de Cidades

Viana, Vila Velha e Vitória), 8 se encontram entre os 10 menores usos de agrotóxicos por estabelecimentos agropecuários (Bom Jesus do Norte, Mucurici, Piúma, Ponto Belo, São José do Calçado, Viana, Vila Velha e Vitória), 9 se encontram entre os 10 com menores áreas cobertas por lavoura (Bom Jesus do Norte, Ecoporanga, Mucurici, Piúma, Ponto Belo, Presidente Kennedy, Serra, Vila Velha e Vitória) e 5 representam os municípios com menos estabelecimentos agropecuários no estado (Bom Jesus do Norte, Piúma, Serra, Vila Velha e Vitória ).

\subsection{AGROTÓXICOS ASSOCIADOS AS CULTURAS}

Analisando os dados do IBAMA (2020), observa-se que a distribuição das vendas dos I.A.'s se dá de forma desigual no estado, onde poucos I.A.'s são comercializados em larga escala enquanto muitos possuem vendas reduzidas. Dos 87 I.A.'s comercializados entre os anos de 2009 e 2018 com registro ativo atualmente no IDAF, apenas 4 possuem comercializações totais superiores a 1.000 toneladas e apenas 1 apresenta valor superior a 10.000 toneladas. Se somados os totais comercializados dos 5 I.A.'s mais vendidos, estes são, sozinhos, responsáveis por $81 \%$ do total, 28027,52 toneladas de agrotóxicos comercializadas no estado durante o período analisado. O herbicida glifosato, I.A. mais consumido, é responsável por aproximadamente $56 \%$ do total comercializado no estado, com 15.762,67 toneladas, valor aproximadamente 4 vezes superior ao segundo colocado, o herbicida 2,4D, responsável por aproximadamente $11 \%$ (3.222,21 toneladas).

A cultura do milho é aquela com mais agrotóxicos registrados para comercialização no IDAF, com 521 produtos. Os 5 compostos mais comercializados para o milho são o glifosato, 2,4-D, mancozebe, clorpirifós e flutriafol. $\mathrm{O}$ café vem em segundo lugar, com 460 produtos registrados no estado. Os 5 compostos com uso autorizado mais comercializados para cultura são o glifosato, o 2,4-D, o mancozebe, o clorpirifós e o flutriafol. A cana-de-açúcar ocupa a terceira colocação, com 403 produtos registrados. Os 5 compostos autorizados para a cultura mais comercializados são glifosato, 2,4-D, mancozebe, flutriafol e dicloreto de paraquate. A banana é a cultura com menos agrotóxicos registrados, ocupando a quarta colocação com 141 produtos, número expressivamente menor que as demais. Para esta cultura, os compostos mais comercializados são glifosato, mancozebe, clorpirifós, flutriafol e dicloreto de paraquate. Nota-se alguma convergência entre os compostos encontrados. Os I.A.'s glifosato, I.A. mais comercializado no estado; mancozebe, terceiro I.A. mais vendido no estado (1.666,34 ton); e flutriafol, quinto mais vendido (776,73 ton), merecem destaque por se encontrarem entre os 5 mais comercializados dentre os agrotóxicos autorizados para as quatro culturas analisadas no presente estudo.

A água é o único compartimento ambiental com parâmetros de qualidade para agrotóxicos previstos por lei. Contudo, apesar de estar localizado em uma das regiões do país com maior disponibilidade de informações sobre qualidade da água de consumo humano (Barbosa et al., 2015;Oliveira et al., 2019), o Espírito Santo, apresenta um baixo número de municípios com dados para agrotóxicos e carências para operacionalização do sistema (Altoé, 2018). Segundo o autor, em 2014 apenas 19 \% dos municípios capixabas monitoraram agrotóxicos na água, número que se reduziu ao longo dos últimos anos, chegando a aproximadamente 6 \% em 2018 segundo dados do Sistema de Informação de Vigilância da Qualidade da Água para Consumo Humano (Ministério da Saúde, 2020). 


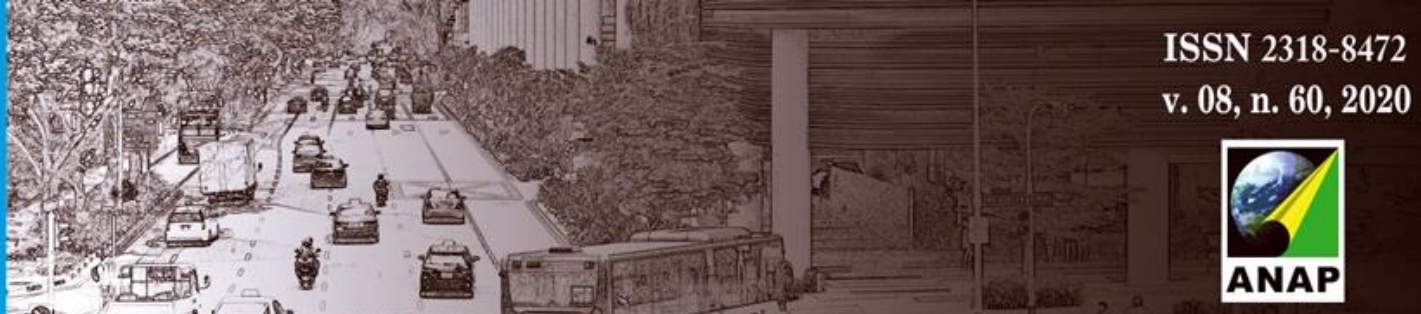

Revista Nacional de

Gerenciamento de Cidades

Apenas o glifosato, dentre os compostos elencados nesse estudo, é considerado nos parâmetros de qualidade da água concomitantemente nas Resoluções CONAMA n 357 que trata de mananciais superficiais, e CONAMA $n^{\circ} 396$ que trata de águas subterrâneas, além do anexo XX da Portaria de Consolidação $n^{\circ} 5$ de 2017, que trata da água para consumo humano. O I.A. mancozebe é considerado apenas na $P C n^{\circ} 5$ de 2017, enquanto o flutriafol não é citado em nenhuma das três legislações (Brasil, 2005,2008 , 2017). Esse fato é preocupante da perspectiva ecológica e sanitária. Segundo a última edição do Relatório Nacional de Vigilância em Saúde de Populações Expostas a Agrotóxicos, o Espírito Santo se encontra acima do dobro da média nacional de intoxicações por agrotóxicos entre 2007 e 2015. Reforçando a necessidade de estados legislarem no âmbito ambiental devido suas especificidades.

Quanto a classificação de toxicidade ambiental, glifosato e mancozebe se enquadram na Classe III Produto Perigoso ao Meio Ambiente, enquanto o flutriafol está na Classe II - Produto Muito Perigoso ao Meio Ambiente. A literatura demonstra relações diretas entre os agrotóxicos destacados e efeitos negativos de ordem ambiental, reforçando o seu risco. O glifosato, I.A. mais consumido no Brasil (IBAMA, 2020), mostra ligação a quedas na resposta imune de mexilhões a proliferação de patógenos oportunistas (lori et al., 2019), e a distúrbios metabólicos em peixes após longa exposição (Li et al., 2017). O fungicida mancozebe, também amplamente consumido no Brasil, demostrou potencial de interferência na reprodução e desenvolvimento de invertebrados em solos brasileiros (Carniel et al., 2019) e também no sistema reprodutivo feminino em mamíferos, através de danos nas células granulosas do ovário (Paro et al., 2012). Lopez-Antia et al., 2018) encontraram evidências de que a ingestão de alimentos contaminados pelo fungicida flutriafol podem reduzir em até $50 \%$ o tamanho da prole de algumas aves.

O estado não conta com legislação própria com padrões de qualidade da água ou para os demais componentes ambientais, contudo, os resultados obtidos no presente estudo podem sugerir a necessidade de uma legislação a nível estadual para balizar o uso dos agrotóxicos identificados, assim como minimizar seus riscos.

\section{CONCLUSÃO}

A metodologia proposta se mostrou eficaz na determinação das culturas agrícolas mais representativas no estado do Espírito Santo, assim como os municípios sob risco de contaminação ambiental e os agrotóxicos associados a cada uma das culturas podendo, assim, auxiliar na gestão ambiental de seu território. As culturas que se destacam no cenário agrícola do estado são o café, a cana-de-açúcar, o milho e banana. O café mostrou-se como a cultura com maior risco de contaminação ambiental por agrotóxicos, tendo o maior número de municípios incluídos na classe de alto risco. A banana por sua vez se apresentou como a cultura de menor risco associado.

Quanto aos agrotóxicos associados as culturas, glifosato, mancozebe e flutriafol são os mais difundidos. Tal resultado destaca a necessidade de cautela no emprego de tais substâncias visto seu potencial tóxico. A predominância de áreas de médio risco de contaminação no território do estado corrobora com essa hipótese uma vez que a falta de manejo adequado dos agrotóxicos nestas regiões 
